\title{
Working memory training does not improve executive functioning or fluid intelligence
}

\author{
Jose A. Rodas ${ }^{1,2}$ and Ciara M. Greene ${ }^{1}$ \\ ${ }^{1}$ School of Psychology, University College Dublin \\ ${ }^{2}$ Faculty of Psychology, University of Guayaquil
}

\section{Author Note}

Jose A. Rodas (D) https://orcid.org/0000-0001-8217-0238

Ciara M. Greene (iD https://orcid.org/0000-0002-8833-9046

This study was registered with AsPredicted.org (\#24178)

We have no conflicts of interest to disclose. This research was funded by 'Programa de Becas para Docentes Universitarios de la Universidad de Guayaquil' awarded to Jose A. Rodas.

Correspondence concerning this article should be addressed to Jose A. Rodas, School of Psychology, Newman Building, University College Dublin, Belfield, D4, Ireland. Email: jose.rodas@ucdconnect.ie 


\begin{abstract}
Several studies have reported that cognitive training can lead to improvements of complex mental skills such as intelligence. However, attempts to replicate these findings have not been very successful with many studies reporting lack of transferable effects on cognitive processes unrelated to the training task. On the other hand, transfer effects on cognitive processes closely related to the training task have been more commonly reported. In this study, we investigated the effects of a frequently used working-memory training programme on fluid intelligence and specific executive functions (updating, inhibition, switching, the focus of attention, and sustained attention). We remedied common issues with previous training studies by using an active control group, using more than one instrument to assess each function, and including a larger sample size. The experimental group showed significant improvement in the training task, indicating strong practice effects. However, no evidence of training-specific transfer was found in any of the variables investigated, and we could not replicate any of the previous findings reported. Participants in both the training and control group showed posttraining improvements in most of the outcome variables, suggesting that practice effects can be found even when a task is only performed twice. We conclude by discussing possible explanations for the differences between our results and those reported in prior studies, and recommend that any claims of improvement should be supported by studies capable of replicating them.
\end{abstract}

Keywords: n-back, working memory, executive functions, cognitive training, randomised controlled trial 
EFFECTS OF AN N-BACK TRAINING ON EXECUTIVE FUNCTIONS

\section{Can we improve executive functions with the n-back training programme? Results}

\section{from a randomised controlled trial}

Efforts to improve human cognitive performance are not new (Jensen, 1998). However, during the last two decades, it has turned into an appealing field of study for many researchers. Part of this increased interest comes from several studies investigating working memory (WM) training programmes that reported achieving significant improvements in WM and fluid intelligence (Gf; Jaeggi et al., 2008;

Klingberg et al., 2002; Olesen et al., 2004), two different components of cognition that are key to information processing, learning, and problem-solving (Ackerman et al., 2005). These results provided evidence that the effects of a training programme could be generalized to untrained areas, a finding with strong practical and theoretical implications: If broad and complex mental functions such as $G f$ and WM can be improved it could also be possible to restore specific mental functions known to be affected by psychopathologies or cognitive disabilities. Several studies followed, presenting new WM training programmes and studying programmes that had already been shown to be effective (e.g. Harrison et al., 2013; McNab et al., 2009; Schmiedek, 2010; Smith et al., 2009). However, replication of the positive effects previously reported has proved elusive. The n-back training programme designed by Jaeggi et al. (2008) is one of the programmes that has garnered the most attention, probably due to the significant gains in $G f$ reported in most of the studies performed by the original author (a review of these studies can be found in Au et al., 2015). One important aspect of this training is that several researchers have reported improvements that transfer to several other measures. This includes studies that have found significant improvements in tasks similar to those used during training (i.e. near transfer; Blacker et al., 2017; 
Soveri et al., 2017); in other tasks also assessing WM or closely related to the n-back task (i.e. intermediate transfer), such as working memory updating (Küper \& Karbach, 2016) or post-error performance ( $\mathrm{Li}$ et al., 2020); and in tasks assessing cognitive processes only partially dependent on WM (i.e. far transfer), such as Gf (Jaeggi et al., 2008), verbal fluency, or implicit learning (Heinzel et al., 2014). The number of studies testing this particular training programme has allowed researchers to perform several meta-analyses reviewing its transferable effects, however, the results have been mixed (for significant transferable effects see Au et al., 2015, 2016; or lack of transferable effects see Melby-Lervåg \& Hulme, 2016).

\section{The n-back Task and Training Programme}

The n-back training programme is based on the n-back task, an instrument that has been widely used in the assessment of WM (Owen et al., 2005; Redick \& Lindsey, 2013). The basic structure of an n-back task consists of a stream of stimuli presented to the participant, who is instructed to indicate each time the stimulus currently presented is the same that the one presented $n$ trials before. For example, if $n$ has been set at 2 , participants are expected to hold in their memory only the last two items presented and discard any other items. Difficulty is controlled by increasing or decreasing $n$ as a higher $n$ makes the task more difficult. The type of stimuli presented can vary significantly, resulting in very different tasks following the same n-back structure. For example, participants could be asked to respond to printed letters (e.g. Harvey et al., 2005), spatial locations (e.g. Stephenson \& Halpern, 2013) or the pitch of a sound (e.g. Rinne et al., 2009). The training programme based on this task consists of practising for 20 days with a version of the n-back task that adapts its difficulty to the performance of 
each participant. Thus, the task becomes more difficult as the participant's skill improves.

Despite the frequent use of the n-back task in memory research, some researchers have questioned its real value in the assessment of WM. These concerns have mostly related to two issues: 1) n-back task performance is only weakly correlated with complex span tasks (Jaeggi, Buschkuehl, et al., 2010; Oberauer, 2005) a type of task also commonly used for assessing the WM system, and 2) because the specific processes involved in the performance of the n-back task have not been sufficiently identified.

WM is thought to be composed of a storage component and a processing component (Baddeley, 2012). Complex span tasks tend to assess WM in a very straight forward manner, requiring participants to store and manipulate information by interchangeably presenting stimuli that must be remembered (e.g. letters) and problems that need to be solved (e.g. solving an arithmetic problem), thus recruiting the two main components of WM. This type of task should not be confused with simple span tasks, where only the storage component is recruited since participants are only expected to recall items presented serially. In the case of the n-back task, the processes of storage and manipulation are not as clearly identified as in the complex span tasks. The n-back task requires the continuous monitoring of stimuli in order to update the contents of short-term memory and protect them from interference. From this point of view, performance on the task may depend more on monitoring of information than on storage and processing. Some authors have provided evidence supporting this view (Gray et al., 2003; Kane et al., 2007), observing that the control of attention plays a more important role in performance of the $n$-bask task than serially recalling items from short-term 
memory, particularly when compared to complex span tasks. In a study comparing

different WM measures, including some complex span tasks (Waris et al., 2017), it was found that the n-back task had the highest loading on a general WM factor, a factor related to high-level processes such as intelligence. These findings would seem to indicate that n-back task performance depends more on certain functions in charge of controlling thought and behaviour, known as executive functions (EFs), than the complex span tasks do. Given this dependency of the n-back task on EF, it is unsurprising to find that some studies using the n-back training programme have reported improvements in specific EFs as a result of training.

\section{The n-back Training Programme and Executive Functions}

EFs have been traditionally evaluated as a single complex process (Welsh et al., 1991), however, recent years have seen a trend towards examining individual EFs in more detail in order to understand their individual input to thought and behaviour regulation (Diamond, 2013; Miyake et al., 2000). Several cognitive training studies have reported improvements in some EFs after training with the n-back task. For instance, two separate studies using different versions of the n-back task reported an expansion of the focus of attention (Lilienthal et al., 2013; Verhaeghen et al., 2004). This particular function is in charge of selecting specific items within short-term memory and placing them in a privileged access space of memory for processing. The focus of attention is of very limited capacity (Cowan, 2011; McElree, 2001; Olivers et al., 2011) and has been observed to exert a strong effect in guiding attention when compared to other items in short-term memory (Greene et al., 2015). The possibility of expanding the capacity or functionality of the focus of attention would result in an increased amount of information that can be processed at any given time as more items 
can be held within this privileged space. The two studies mentioned above used very different instruments and methodologies for evaluating the increase in capacity of the focus of attention. In the study by Lilienthal et al. (2013) for example, the focus of attention was measured as the number of items that can be grasped by attentional processes alone, without active updating or rehearsal of items in short-term memory. Participants heard a series of digits recited at a pace of 4 digits per second and were asked to recall the most recent digits in order of presentation. The speed at which the digits were recited prevented participants from rehearsing the numbers or actively updating the contents of WM. Verhaeghen et al. (2004), on the other hand, looked at the accessibility of the information held in the focus of attention by contrasting the response time (RT) needed to access items within short-term memory and the focus of attention. It has been found that there is a significant gap in RT between accessing one item and more than one item (McElree, 2006). This gap in RT is not found when accessing any other number of items. On the contrary, the RT registered when accessing two, three or four items does not seem to vary significantly. This is taken as an indication that only one item can be stored in the privileged space of the focus of attention. By the end of the training programme Verhaeghen et al. (2004) found that the gap between one and more than one items disappeared and was now observed to be between four and five items. Results from the study by Lilienthal et al.(2013) were not as substantial, as the number of items increased from 3.38 to 3.81 items.

At least two studies (Clouter, 2013; Colom et al., 2013) have investigated the effects of the n-back training programme on attentional inhibition, an EF that controls the impulse to direct attention to salient stimuli. Across four tasks, the authors of these studies assessed attentional inhibition as the difference in reaction time between 
incongruent and congruent trials in Stroop or flanker-type tasks. No significant effects of the training regimen were observed in three of the four tasks. However, Clouter (2013) also considered the number of errors made in the analysis of one of these tasks and found that, although both the training and the control group reduced their RTs for both types of trials, the control group did so at the expense of an increased error rate, indicating that only the experimental group experienced a real improvement on the task. This level of analysis was not performed on the other three tasks.

Improvements have also been reported in the updating process of WM (Salminen et al., 2012; Soveri et al., 2017), arguably one of the main components of the n-back task. This EF is responsible for the replacement and protection of information within the WM storage space and involves several sub-processes (Kessler \& Oberauer, 2014). Two different aspects of the updating process are commonly assessed: (1) the time required to update information held in the focus of attention, and (2) the capacity to update the information held within the WM system and protect it from interference. Improvements were only found in tasks requiring the protection of information from interference.

Although EFs such as inhibition, the focus of attention, and the updating of WM have shown evidence of improvement following training, the n-back task relies on other cognitive processes that could also be potentially affected by training. For example, the efficacy of switching between tasks or mental sets and the capacity to sustain attention, which has received little attention in cognitive training. The relevance of these two processes to n-back performance is evident when considering that sustained attention is necessary for the monitoring of internal and external stimuli, and that performance of the task requires attention to switch between elements within short-term memory. The 
role of switching as an EF is undisputed (Diamond, 2013; Miyake et al., 2000), but this is not the case of sustained attention which is not usually included among EFs. However, it has been observed through behavioural and neuroimaging studies that sustained attention, working memory, and EFs might share common mechanisms (Silver \& Feldman, 2005; Takahashi et al., 2010). For this reason, if the n-back training is capable of inducing transferable effects, sustained attention and switching could also be improved.

\section{Methodological Limitations Commonly Found in Cognitive Training Studies}

Many of the methodological decisions of the early cognitive training studies have been questioned, and some have argued that the use of insufficient control conditions in their designs has been the main reason for the improvements reported (Shipstead et al., 2012). For example, evidence has been provided showing that comparing a group of participants that underwent training with a no-contact control group (passive control) usually overestimates the effects of training in comparison to a control group undergoing a "placebo" form of training (active control; Melby-Lervåg \& Hulme, 2016). Significant placebo effects have been found in cognitive training studies (Boot et al., 2013; Foroughi et al., 2016), making active control groups important to consider when designing cognitive training studies. Au et al. (2020) have argued that the use of active control groups might not be enough for controlling these effects, and even more, that the apparent difference in effect size observed are not significant enough to be considered making both type of control groups equally valid.

The size of the groups used in many studies has also been a matter of debate, as many of these studies tend to have small sample sizes and are hence underpowered (see Schmiedek, 2016 for a discussion of this issue). One other important aspect that studies 
need to consider in their design is the practice effects of doing a task. Improvements in the performance of a task as a result of doing it on repeated occasions (i.e. as part of a training regime) is not necessarily an indication of improvement at a construct level. In order to avoid this problem, different instruments can be used for training and assessment in order to distinguish practice effects from real cognitive improvement (Shipstead et al., 2012). Many of these limitations have been overcome to some extent in more recent studies where transfer effects tend to be more modest (e.g. Baniqued et al., 2015; Brem et al., 2018). However, some of these limitations, such as small sample sizes, are still present in studies focussing on very specific populations, such as older adults with cognitive impairments (for a meta-analysis see Hill et al., 2017) or children with attention-deficit/hyperactivity disorder (for a meta-analysis see Cortese et al., 2015). Small sample sizes in these populations could be due to the difficulties involved in finding enough participants who are willing to undergo the training and capable of maintaining the motivation necessary to properly follow the training regimen until the end.

One of the major limitations in the field of cognitive training is the difficulty of replicating many of the findings reported by individual studies (see Simons et al., 2016 for a review), casting serious doubts on their effectiveness. Many replication efforts have focused on Gf(e.g. Dougherty et al., 2016; Redick et al., 2013; Stephenson \& Halpern, 2013); considering that several EFs have been implicated in the performance of the n-back task, it is surprising that relatively little attention has been paid to analysing the effect of this training on specific EFs. In general, far transfer effects have been difficult to attain with WM training programmes (e.g. Sala \& Gobet, 2017; Schwaighofer et al., 2015). However, near and intermediate transfer effects 
(improvements in similar tasks and on different tasks assessing the same construct respectively) to other WM tasks are far more common in cognitive training literature, and several reports have supported the potential of cognitive training to achieve these type of effects (Melby-Lervåg \& Hulme, 2013; Peijnenborgh et al., 2016). Given that several EFs are recruited for performing the n-back task transferable effects to these EFs should be easier to attain as compared to other outcomes considered as far-transfer, such as arithmetic skills or verbal abilities, where other factors, such as prior knowledge, also play an important role.

One other important limitation that is becoming increasingly more relevant in cognitive psychology studies is the prior exposure of the sample to cognitive tasks or testing procedures in general, which in some cases can be extensive as the use of online platforms for recruiting and evaluating participants is becoming more common (Antoun et al., 2016; Lane et al., 2015). This prior exposure can potentially improve test performance, however this improvement is not related to real knowledge in the subject evaluated, but rather to the methods of assessment (Millman et al., 1965). This phenomenon has been called test-wiseness and has been investigated in several fields for some time (e.g. Sarnacki, 1979; Willing et al., 2015). Cognitive tasks are expected to require the use of specific cognitive functions to be performed successfully. However, it has been observed that prior exposure to different assessment situations can have a significant effect on test performance that is not directly accounted for the ability being measured. This is observed on a range of measures, including tests of intelligence (Cave \& Grieve, 2009; Rosselli \& Ardila, 2003; Shuttleworth-Edwards et al., 2004), and has implications for the validity of the scores obtained. Although it might not be possible to fully eliminate the effect of this factor in an outcome score a possible 
solution can be to recruit participants with limited exposure to the test situation at hand (e.g. Ellis \& Ryan, 2003; Rogers \& Bateson, 1991).

\section{The Current Study}

The present study seeks to accomplish three things: (a) replicate previous findings reported in several studies using the n-back training programme originally proposed by Jaeggi et al. (2008) regarding its effects on $G f$ (far-transfer); (b) evaluate the effects of the n-back training on short-term memory and several EFs, namely, the focus of attention, inhibition, sustained attention, and the updating process of WM (intermediate-transfer); and (c) examine the effects of training in a sample with very limited exposure to computerised cognitive tasks.

In order to do this, the impact of a visuospatial n-back training programme was evaluated in a group of healthy Ecuadorian adults. Psychology research is very limited in Ecuadorian universities (Capella \& Andrade, 2017), and instruments used in applied psychology are commonly scored using norms from other populations, significantly limiting the exposure of this population to this type of testing (observations from applied psychology practice in the Ecuadorian population can be seen in Capella, 2019). $G f$, short-term memory and EFs related to the n-back task were evaluated pre- and postintervention. The assessment of each EF included two tasks, each evaluating a different aspect of the same function. Efforts were made to include tasks used in previous studies reporting improvements in EFs. This was done as an attempt to replicate these findings.

\section{Method}

\section{Preregistration}

The study design and analysis was preregistered at http://aspredicted.org/blind.php? $\mathrm{x}=\mathrm{dp} 34 \mathrm{~s} 8$. 


\section{Participants}

The initial sample consisted of 186 participants $(127$ female, mean age $=22.4$, $\mathrm{SD}=7.26$ ), who took part in the first assessment session and were randomly allocated to the experimental group or control group using a pseudo-random computer-generated number. From this initial sample, 83 were assigned to the control group and 76 to the experimental group. The remaining 27 participants decided not to continue with the study after the initial assessment, and thus were not assigned to any group. Ninety-eight participants completed the training programme and returned for the post-training assessment. At the final assessment, the experimental group included 42 participants (30 female, mean age $=22.4, \mathrm{SD}=7.25)$ and the control group included 56 participants $(39$ female, mean age $=23.3, \mathrm{SD}=7.94)$. Ethical approval was granted by the University of Guayaquil and the sample consisted mostly of undergraduate psychology students. No compensation was offered for participation. A power analysis conducted in $\mathrm{G}^{*}$ Power 3.1 (Faul et al., 2007) suggested that with this sample size our study has $80 \%$ power to detect small effect sizes $\left(n_{p}^{2}=0.014\right)$ in the interaction of a mixed ANOVA.

\section{Pre- and post-training Assessment Instruments}

The assessment consisted of eleven instruments in total. Nine of the instruments were presented on a computer and two were paper-based (Test of Nonverbal Intelligence and backward digit span task). Figure 1 depicts the eight tasks using visual stimuli. The running span, continuous performance, and backwards digit span tasks are not depicted as they are composed of auditory stimuli only. PsychoPy2 (Peirce, 2008) was used to create all computer tasks except for the Stop-signal task, for which the STOP-IT program was used (Verbruggen et al., 2008 available from https://osf.io/wuhpv/). All instructions for the tasks were given verbally by the examiner 
and presented on screen. The practice trials were monitored by the researcher in order to confirm that the tasks were properly understood. Due to space restrictions, only a brief description of the instruments is presented here. More detailed information can be found in supplemental materials.

\section{Fluid Intelligence (Gf)}

Test of Non-Verbal Intelligence, Second Edition (TONI; Brown et al., 2009).

Depicted in Figure 1a. The test consisted of abstract patterns with a missing piece. Participants were required to solve each problem by completing the pattern in order to progress to the next one. All problems were presented in increasing order of difficulty. The original test includes two sets of 55 abstract patters that produce equivalent scores, allowing for the evaluation of a participant on two different occasions without eliciting practice effects. For the present study, items from the two sets were pooled and divided among three sets (A, B, and C), similar to what has been done in other studies (e.g. Colom et al., 2013; Jaeggi et al., 2014). In order to have sets of similar difficulty, each item was given a score according to their original rank order and the new sets were created taking into consideration that each summed a similar score when combining the items. The outcome score was the number of correct items.

\section{Short-Term Memory}

Backward Digit Span. Sets of digits were recited at a pace of one digit per second to participants and they were instructed to repeat them in reverse order. The length of the series ranged from two to nine digits and these were presented in ascending order starting from two-digit series. Two series for each length were presented to the participants and the task was stopped if they could not recall at least 
one of the series correctly. Each series were created using all digits from 1 to 9 and randomising their order. Each digit could appear in each series only one time.

\section{Focus of Attention}

Running Span Task (Lilienthal et al., 2013). A series of auditory digits was presented via computer at a pace of $250 \mathrm{~ms}$ per digit. Participants were instructed to listen to the series, and then type as many of the most recent digits from the series as they could remember in the order they were presented. The outcome score was the mean number of digits correctly recalled.

Columns n-back (Verhaeghen et al., 2004). Depicted in Figure 1b. Digits were presented one at a time in a reading order inside an imaginary grid (forming rows and columns), and the participant was asked to indicate via keypress if the digit currently presented was the same as the one presented immediately above. Each keypress made the current digit disappear and the next digit appear. Digits appeared in either one or two columns, requiring participants to remember either one or two numbers at any one time. The outcome score was the difference in response time (RT) between the 1-column condition and the 2-column condition. A reduction in the difference between these two scores represents increased accessibility of information within the focus of attention. The number of errors in both conditions is also reported.

\section{Inhibition}

Stop-Signal Task (Verbruggen et al., 2008). Depicted in Figure 1c. This was a go/no go task. Participants were presented with visual stimuli and were required to press a key as soon as they could when a figure (a circle or a square) was presented on the screen. In some trials, however, a signal (a beep sound) that indicated not to press the key on that trial was presented right after the presentation of the visual stimuli. The outcome 
score is the Stop Signal Reaction Time (SSRT), which represents the time taken to inhibit the motor response of pressing the key. Several procedures are used to determine this value, however, we used the one described in Verbruggen et al. (2008).

Colour Word Stroop (Kane \& Engle, 2003; Rodas \& Greene, 2020a; Stroop, 1935). Depicted in Figure 1d. The words "red", "green" and "blue" were presented on a black computer screen in red, green or blue font. Each word presentation is considered a trial, and these could either be congruent (when the word and colour matched) or incongruent (when the word and colour did not match). Participants were required to press a key depending on the font colour of the word and not on the meaning of the word. RT was registered on each keypress. The outcome variables were the difference between the RTs of the incongruent and congruent trials. The number of errors has also been reported.

\section{Updating}

Letter Memory Task (Miyake et al., 2000; Rodas \& Greene, 2020a). Depicted in Figure 1e. Series of letters were presented to the participants one at a time and the participant was asked to remember the last four digits of each series and type them into the computer. As the number of digits to be presented was unknown by the participant, this required an updating process in the short-term memory whereby the participant must incorporate the newly presented letter into short-term memory and discard the now fifth letter. The outcome variable was the total number of letter correctly recalled across all blocks of trials (sets of letters).

Arithmetic-Updating task adapted from Oberauer (2002). Depicted in Figure 1f. Two boxes were presented on the screen one on top of the other. At the start of the task, a single digit is presented in each box. After memorising the digit, the participant was required to press a key, which made those digits disappear and a new digit preceded by 
a plus or minus symbol (e.g. -2) appear inside one of the boxes. The participant was expected to add or subtract this number to the number previously contained within that box. The participant was instructed to press the key when finished performing the mental calculation which would cause a new symbol and digit (e.g. +4$)$ to appear. Each digit presentation modified the content of the box and, after an unspecified number of updating trials, the participant was asked to recall the final total of each box. The outcome score was the mean RT registered when the content of a box had to be updated consecutively, that is, when the new digit appeared in the same box.

\section{Focus switching}

Arithmetic-Updating Task Adapted from Oberauer (2002). Depicted in Figure 1f.

This was the same task used for evaluating the updating process of working memory content. However, in this case, the outcome score was the mean RT registered when the participant had to update the content of the box that was not immediately updated, that is, when the new digit appeared in the other box. This required switch mental set from the content of one box to the other.

Letter-Updating Task (Kessler \& Oberauer, 2014). Depicted in Figure 1g. Four white boxes, were presented horizontally on the middle of the screen and within each box, a letter was presented. The participant was required to remember these letters and update the content of the box as new letters appeared inside them. Each keypress of the participant caused all the content of the boxes to change, either by presenting a new letter or an asterisk. An asterisk inside a box indicated that the content of the box remained the same (contained the same letter) and participants must recall the information presented in the last trial. A new letter inside a box indicated that the content of the box had been updated, requiring the participant to forget the previous 
letter and now remember the new one. Each new letter presented required the participant to switch their mental set from remembering the letter previously presented in that box (recall) to updating the content of that box with the new letter. After a number of trials unknown by the participant, they were asked to recall the last letter contained within each box. The appearance of letters and asterisks within the four boxes created different patterns (e.g. updating-updating-recall-updating). The mean RT from the patterns requiring three or four switches was used as the outcome score.

\section{Sustained attention}

\section{Sustained Attention to Response Task (SART; Robertson et al., 1997; Rodas \&}

Greene, 2020a). Depicted in Figure 1h. A string of digits (1 to 9) was presented on the screen each followed by a mask (an X inside a circle). The participant was required to press a key each time any number other than 3 appeared on the screen, and to withhold the response when the number 3 was shown. The outcome score used was the number of errors by commission, this is, the number of times the participant pressed the key when the digit 3 appeared.

Continuous Performance Task (CPT). This is a modified version of the task developed by Rosvold et al. (1956). This task is similar to the SART as the participant was presented with a string of digits and was instructed to press a key or to withhold from pressing it depending on the digit presented. In this case, digits were presented auditorily and the participant was required to press a key when the number 3 was heard. All digits were recited by a computer. The outcome score was the number of errors by omissions, this is, the number of times the participant failed to press the key when the number 3 was recited. 


\section{Training tasks}

Two different tasks were used for training, depending on the participant's assignment to the training or control group (see Figure 2 for an illustration).

Visuospatial n-back task (experimental group) (Jaeggi et al., 2008). This task was similar to that used by Jaeggi et al. (2008), although only the visuospatial component was used. The training task consisted of a series of squares presented at eight possible locations within a $3 \times 3$ grid. Each trial consisted of a square appearing on the screen for one second followed by an interstimulus interval of two seconds. Participants were instructed to press the space bar each time the square appeared in the same space it was $n$ trials before. Trials were grouped into blocks of $20+n$, where 6 of these were target trials and the rest consisted of random positions within the grid. The task difficulty varied by changing the value of $n$, which changed automatically depending on the participant's performance during each block. More than five errors during a block made $n$ decrease by 1 ; less than three errors made $n$ increase by 1 ; and in all other cases, $n$ remained unchanged. An error could be a missed target trial or a keypress on a no-target trial. The first trial of the first session always started with $n=1$. Figure $2 \mathrm{~b}$ depicts an example of this task with $n=2$.

Visuospatial 1-back task (control group). Depicted in Figure 2a. This task was identical to the visuospatial n-back task except that $n$ was equal to 1 on all trials, and did not adapt to participants' performance.

[FIGURE 2 HERE]

\section{Procedure}

The study was advertised via flyers and classrooms visits at the School of Psychology of the University of Guayaquil. Participants attended the University to 
complete the first assessment session, after which they were assigned to either the experimental or control group, instructed in how to do their assigned task, and all the necessary software for the training programme was installed in their laptops or given to them along with detailed instructions about how to install the software. After completing the training regime (see below), they came back for the post-training assessment session. The two assessment sessions were identical, with the exception that the order of tasks was counterbalanced between sessions and participants using a Latin Square. Each session took approximately 2.5 hours to be completed and participants attended individually. The three sets of items available for the TONI (A, B, and C) were always presented sequentially, however, the starting set used on each participant was determined randomly.

Between the two assessment sessions, participants completed the training programme, which consisted of 20 training sessions distributed across four weeks; participants were asked to complete five sessions per week. A minimum of 16 training sessions was required for a participant to return to the post-training assessment. All sessions were performed at each participant's home. The training programmes for both the experimental and control group were almost identical, with the only difference being the task used for training. The experimental group used the visuospatial n-back task, which is adaptive, whereas the control group used the fixed visuospatial 1-back task. Participants completed 20 blocks of trials in each session, which would usually take approximately 25 minutes. At the beginning of each training session, participants were asked to score their motivation for doing the training on that day using a number between 1 to 5 , where 1 represented no motivation at all and 5 greatly motivated. After completing a session, the computer program used for running the task in their 
computers created a file containing data from the session. Participants were instructed to send this file via email in order for us to monitor their progress. When a participant did not send the file for more than three consecutive days, a researcher contacted them by email as a reminder to do the training.

Our preregistered study design initially included a follow-up assessment, to be completed two months after the post-training assessment. However, the COVID-19 pandemic severely affected this assessment, and only 20 participants were able to complete the follow-up within the stated timeframe. For this reason, it was decided to exclude these data from this report. The full dataset, including data from participants who completed the follow-up assessment, may be viewed online at https://osf.io/b45ay/.

\section{Results}

Table 1 summarises descriptive information from all the main assessment measures used in this study grouped by condition (experimental group and control group) and time (pre- and post-training). Note that the number of participants across measures presents small variations due to lost data in some tasks. In all cases, the lost data was caused by technical problems on the computers during the assessment. The mean number of sessions completed by the control group was $19.84(\mathrm{SD}=0.65 ; 33 \%$ did not complete the programme) and for the experimental group 19.1 sessions $(\mathrm{SD}=$ $1.43 ; 45 \%$ did not complete the programme). Two participants completed 16 and 20 sessions respectively, but did not return for the post-training assessment.

[TABLE 1 HERE]

Differences at baseline between groups were analysed with a series of t-tests (Welch's t-test) on all measures. No significant difference between the training and 
control groups was found in any of the measures (all p's $>0.07$ ). Results from these analyses can be found in supplemental materials (Table S-2).

The experimental group's n-back performance across sessions was analysed using a repeated measures ANOVA with the mean level of $n$ achieved in each of the 20 sessions. A significant effect of session was found $\left(\mathrm{F}(19,456)=9.54, \mathrm{p}=<0.001, \eta_{p}^{2}=\right.$ 0.285 ) indicating an improvement in performance of the n-back task across sessions. A polynomial contrast revealed that this increase followed a quadratic trend $(\mathrm{F}(1,24)=$ $7.68, \mathrm{p}=0.01)$. Figure 3 depicts the mean progress of the experimental group during the programme.

\section{[FIGURE 3 HERE]}

In order to assess the effects of training on the different assessment measures, a set of mixed-design ANOVAs were performed, using group (training vs. control) as the between-subjects factor and time (pre- vs. post-training) as the within-subjects factor. Eighteen ANOVAs were performed in total; thus a Bonferroni-corrected alpha level of $0.0028(0.05 / 18)$ was used to determine statistical significance. In accordance with our preregistration, a significant interaction between factors (group and time) would indicate an improvement in the experimental group due to training. Results from these analyses can be found in Table 1; the interaction effect did not reach significance for any of the assessment measures.

There were no main effects of group, however scores from several tasks showed a main effect of time, such that there was a significant improvement from the pretraining assessment to the post-training assessment: Arithmetic-Updating switch $(\mathrm{F}(1$, $\left.94)=23.41, \mathrm{p}<0.001, n_{p}^{2}=0.2\right)$, Columns n-back $\left(\mathrm{F}(1,95)=16.5, \mathrm{p}<0.001, n_{p}^{2}=\right.$ 0.15), CPT omissions $\left(\mathrm{F}(1,94)=12.49, \mathrm{p}<0.001, n_{p}^{2}=0.12\right)$, Letter-Updating $(\mathrm{F}(1$, 
$\left.95)=40.66, \mathrm{p}<0.001, n_{p}^{2}=0.3\right)$, Rapid Span $\left(\mathrm{F}(1,95)=21.5, \mathrm{p}<0.001, n_{p}^{2}=0.18\right)$, and Stroop $\left(\mathrm{F}(1,96)=82.27, \mathrm{p}<0.001, n^{2}{ }_{p}=0.46\right)$. These findings indicate strong practice effects in these measures (see supplemental materials, Table S-3, for further details of these analyses).

\section{[FIGURE 4 HERE]}

\section{Discussion}

In this study, we investigated the effects of the n-back training programme in several EFs, short-term memory and Gf. Some EFs have already been reported to be improved by cognitive training. For example, Lilienthal et al. (2013) and Verhaeghen et al. (2004) found the focus of attention to be improved when assessed with the Running Span and the Columns n-back tasks respectively; Clouter (2013) found improvements in inhibition when evaluating the number of errors in the Stroop task; Salminen et al. (2012) and Soveri et al. (2017) found improvements in the updating process of WM. We attempted to replicate these findings, in some cases using the same assessment tasks (Columns n-back, Running Span task, and Stroop), although with a stronger methodology. We also investigated the effects of training on other cognitive processes suspected to be involved in the performance of the n-back task, namely, switching, sustained attention and short-term memory. Some of the methodological improvements that we implemented included the use of larger sample size, having more than one task to assess each EF, using an active control group, and controlling for baseline differences in performance. Despite these methodological strengths, we did not find improvement as a consequence of training in any of the cognitive processes we investigated, including those functions that have already been reported to be improved, namely, inhibition (Clouter, 2013), the focus of attention (Lilienthal et al., 2013; Verhaeghen et al., 2004), 
and updating (Salminen et al., 2012; Soveri et al., 2017). In relation to $G f$, the attempts to replicate the original improvements reported by Jaeggi et al. (2008) are more numerous and the results have been mixed (for significant improvements see Au et al., 2015; for lack of transferable effects see Melby-Lervåg et al., 2016). In our case, no significant improvements were found.

We speculate that this failure to replicate previous effects of training in EFs may be due to the methodological improvements we implemented. For example, Lilienthal et al. (2013) also investigated the effects of the n-back training on EFs and found improvements in the Running Span task, a task assessing the focus of attention. Their study, however, included a very small sample size $(n=26)$, making it more susceptible to false-positive errors (Forstmeier et al., 2017). Salminen et al. (2012) also investigated the effects of the n-back training on several EFs and found a significant improvement in the updating process of WM. Their study also included a small sample size $(n=38)$. The sample used in our study, in comparison, was significantly larger $(n=98)$, and provided adequate power to detect small effects. In another study by Verhaeghen et al. (2004), a training programme based on the Columns n-back task, the focus of attention was found to be increased after training. However, the outcome of the training was evaluated using participants' performance in the training task across sessions. This significantly affects the validity of the results as improvement in the construct under investigation - working memory ability - could not be distinguished from practice effects. Critically, all of the assessment measures used in the present study were different from the task used for training. Although we used the same task as Verhaegen et al. (2004) to evaluate the focus of attention (the Columns n-back task), our training task and outcome score were different. We used a visuospatial n-back task for training 
and the outcome score was obtained from the difference in RT between one and two columns from the Columns n-back task. This score represents the accessibility to items in the focus of attention (registered in RT), and a reduction in the difference of RT between the 1 column condition and conditions with more than one column has been used as evidence of increased accessibility to items in the focus of attention (McElree, 2001; Verhaeghen et al., 2004).

The last task we used for replication is the Stroop task included in the study by Clouter (2013). As in the study by Clouter, we used the modified version of the Stroop task originally proposed by Kane and Engle (2003). Clouter (2013) found significantly fewer errors in the experimental group, but again, we could not replicate this finding.

An important difference between our study and the studies by Clouter (2013), Lilienthal et al. (2013), and Salminen et al. (2012) is that we used a visuospatial n-back task, while those other studies used a combination of a visuospatial n-back task and auditory n-back task (presenting letters), presenting both types of stimuli simultaneously. This version of the n-back task is known as the dual n-back task and was the task used by Jaeggi et al. (2008) in their first study reporting far-transfer effects on $G f$. Although the use of this more complex form of training could be accounted responsible for the improvements reported by these studies there is little evidence to support this view. For example, Salminen et al. (2012) considered that the dual-tasking required in the dual n-back task would improve the functions of switching. However, their results did not show any improvement in this EF. Even more, Jaeggi, StuderLuethi, et al. (2010) investigated if there were differences in terms of far-transfer effects between the n-back and dual n-back version of the programme and found that both versions were capable of improving $G f$ to the same degree. Other studies have also 
reported improvements in $G f$ using a "single" n-back training (Stephenson \& Halpern, 2013; Studer-Luethi et al., 2012). These results seem to indicate that the use of the dual version of the programme does not contribute significantly to the outcome and that intermediate-transfer effects should still be attainable.

In addition to attempting to replicate findings from prior studies investigating the effects of cognitive training on EFs, we included some important methodological contributions such as the use of more than one task for assessing each EF. Although it is becoming more common in cognitive training research to use more than one task for the assessment (e.g. Minear et al., 2016; Ward et al., 2017), in most of these cases all the tasks used evaluate the same aspect of the EF. This is usually done to allow for the construction of latent variables which reduces the amount of measurement error in the final score (Bollen, 2002). In our study, we opted for the assessment of very different aspects of each EF. Although this decision prevents us from obtaining latent variables, it allows for the assessment of each EF in a more comprehensive way, without reducing the functions to only a few component aspects. For example, our assessment of the updating of WM includes both (a) the complex process of monitoring and protecting the content of short-term memory, assessed by the Letter Memory task, and (b) the time taken to replace its content, assessed by the Arithmetic-Updating task. Although a true improvement at a construct level should manifest in an increased performance of several aspects of the assessed EF, we also considered it possible that the n-back training might only affect certain aspects of the functions - specifically, those aspects more related to performance in the n-back task such as the monitoring process in updating or attentional inhibition in the inhibitory function. As observed in our results, transferable effects were not present in any of the outcome measures analysed. 
We hypothesised that improvements from the n-back training could be easier to attain in some EFs closely related to WM and the n-back task (i.e. focus of attention, switching, inhibition, sustained attention, and updating). Nevertheless, improvements in the n-back task did not transfer to any measure of EF, not even to the Letter Memory updating task (Miyake et al., 2000), a task that shares several structural characteristics with the n-back task. In both cases, stimuli are presented in a stream and a specific number of items need to be updated in WM while older items are discarded. Arguably, the only significant difference between both tasks is the recognition component in the nback task where the $\mathrm{n}^{\text {th }}$ stimulus in memory needs to be identified from the stream of stimuli presented. One important difference between the n-back task used in this study and the Letter Memory task is the type of stimuli used, as one is visuospatial and the latter one is verbal. If transferable effects had occurred we might have expected them to surpass this sort of limitations. This leads us to think that transferable effects only happen on very similar tasks, and not necessarily on similar processes. Practice effect, on the other hand, were conspicuous. Participants in the experimental group showed significantly improvement in the training task, with a very large effect size, according to the benchmarks provided by Cohen (1988). Practice effects were also found in six of the eleven tasks used in this study at the post-training assessment, presenting large effect sizes in all cases.

Pre-registration of the current study is another important strength since it prevents selective reporting of favourable outcomes and analyses. It also prevents the elaboration of postdictions, that is, post hoc rationalisations of unexpected findings (Nosek et al., 2018), and of "fishing expeditions", a term used to identify studies designed with no specific aims (Payne, 1974). The main problem of these practices is 
that the resulting studies are often reported as though they had specific predictions (Nosek et al., 2018), a process known as 'HARKing' (hypothesising after results are known). It has also been observed that these type of practices increase the odds of a study reporting false-positive results (Swaen et al., 2001), with obvious implications for replicability. It is not common for cognitive training studies to be pre-registered (Rodas \& Greene, 2020b), which might explain some of the issues related to replicating some of the positive results found.

It should be noted that the attrition rate in this study is higher than that observed in similar studies (Baniqued et al., 2015; Katz et al., 2014). Probably the main reason for this is related to the characteristics of the sample. Most of the participants who underwent the first assessment session were psychology students, many of whom expressed being very curious about cognitive psychology. It is possible that many of the participants who expressed interest in participating had unrealistic expectations about the training programme and were curious to know more about the instruments used for the assessment of cognition. After undergoing the first assessment sessions they may have realised the level of commitment required, and declined to participate any further. It is important to highlight that experimental psychology in general, and cognitive psychology in particular, are not taught at the University of Guayaquil. Students were therefore extremely naive about cognitive psychology and the instruments commonly used in the field (Rodas \& Greene, 2020a). In this sense, the use of this sample constitutes an important contribution to the study, since it allows for an assessment less affected by the effects of test-wiseness which is very difficult to avoid in studies using samples where psychology research is far more common. Results less mediated by this effect should better represent an improvement at a construct level, which is the true goal 
of cognitive training, instead of the development and use of strategies related to test performance. According to this, our results suggest that transferable effects from cognitive training might be related to the implementation of test-taking strategies in task performance.

In a similar vein, it can be observed that the attrition rate in the experimental group is higher than that found in the control group. Very few of the lapsed participants replied to the researcher's email when asked about their decision to not continue with the programme and, for those who did, the reasons were mostly related to time constraints. It is possible that the participants from the experimental group decided not to continue to follow the programme because it was more challenging than the one followed by the control group.

The lack of transferable effects in this study supports the notion that cognitive training is not effective for improving EFs, which in the case of the training programme used here represent improvements in processes related to the n-back task, that is, intermediate-transfer effects. When looking at previous studies that reported improvements in EF, we identified aspects that could account for those improvements, such as small sample sizes and the same instruments being used for assessment and training, issues that are still sometimes observed in more recent studies. Our findings contradict claims that cognitive training can lead to improvements in untrained areas of cognition. We tested, under controlled conditions, one of the programmes that has presented the most solid results (Au et al., 2015) in transferring improvements to untrained areas and found very strong practice effects, but no evidence of intermediateor far-transfer effects. If cognitive training is really capable of improving untrained cognitive processes more consistent results should be provided from replication studies, 
especially if a programme is being commercialised and used under uncontrolled

conditions, such as in video game consoles or online platforms without careful monitoring (for a review including commercial cognitive training programmes see Simons et al., 2016). We also encourage other authors to pre-register their studies in order to avoid "fishing expeditions" and postdictions, as well to reduce the risk of bias (Sterne et al., 2019). 


\section{References}

Ackerman, P. L., Beier, M. E., \& Boyle, M. O. (2005). Working memory and intelligence: The same or different constructs? Psychological Bulletin, 131(1), 30-60. https://doi.org/10.1037/0033-2909.131.1.30

Antoun, C., Zhang, C., Conrad, F. G., \& Schober, M. F. (2016). Comparisons of online recruitment strategies for convenience samples: Craigslist, Google AdWords, Facebook, and Amazon Mechanical Turk. Field Methods, 28(3), 231-246. https://doi.org/10.1177/1525822X15603149

Au, J., Buschkuehl, M., Duncan, G. J., \& Jaeggi, S. M. (2016). There is no convincing evidence that working memory training is NOT effective: A reply to MelbyLervåg and Hulme (2015). Psychonomic Bulletin \& Review, 3(1), 331-337. https://doi.org/10.3758/s13423-015-0967-4

Au, J., Gibson, B. C., Bunarjo, K., Buschkuehl, M., \& Jaeggi, S. M. (2020). Quantifying the difference between active and passive control groups in cognitive interventions using two meta-analytical approaches. Journal of Cognitive Enhancement, 4(2), 192-210. https://doi.org/10.1007/s41465-020-00164-6

Au, J., Sheehan, E., Tsai, N., Duncan, G. J., Buschkuehl, M., \& Jaeggi, S. M. (2015). Improving fluid intelligence with training on working memory: A meta-analysis. Psychonomic Bulletin \& Review, 22(2), 366-377. https://doi.org/10.3758/s13423-014-0699-x

Baddeley, A. (2012). Working memory: Theories, models, and controversies. Annual Review of Psychology, 63(1), 1-29. https://doi.org/10.1146/annurev-psych$120710-100422$

Baniqued, P. L., Allen, C. M., Kranz, M. B., Johnson, K., Sipolins, A., Dickens, C., Ward, N., Geyer, A., \& Kramer, A. F. (2015). Working memory, reasoning, and task switching training: Transfer effects, limitations, and great expectations? PLOS ONE, 10(11), e0142169. https://doi.org/10.1371/journal.pone.0142169 
Blacker, K. J., Negoita, S., Ewen, J. B., \& Courtney, S. M. (2017). N-back versus complex span working memory training. Journal of Cognitive Enhancement, 1(4), 434-454. https://doi.org/10.1007/s41465-017-0044-1

Bollen, K. A. (2002). Latent variables in psychology and the social sciences. Annual Review of Psychology, 53(1), 605-634.

https://doi.org/10.1146/annurev.psych.53.100901.135239

Boot, W. R., Simons, D. J., Stothart, C., \& Stutts, C. (2013). The pervasive problem with placebos in psychology: Why active control groups are not sufficient to rule out placebo effects. Perspectives on Psychological Science, 8(4), 445-454. https://doi.org/10.1177/1745691613491271

Brem, A.-K., Almquist, J. N.-F., Mansfield, K., Plessow, F., Sella, F., Santarnecchi, E., Orhan, U., McKanna, J., Pavel, M., Mathan, S., Yeung, N., Pascual-Leone, A., Kadosh, R. C., Dillard, M., Erdogmus, D., Kimball, G., \& Myers, E. (2018). Modulating fluid intelligence performance through combined cognitive training and brain stimulation. Neuropsychologia, 118(Part A), 107-114. http://dx.doi.org/10.1016/j.neuropsychologia.2018.04.008

Brown, L., Sherbenou, R. J., \& Johnsen, S. K. (2009). Test de inteligencia no verbal: Manual. TEA Ediciones.

Capella, M. (2019). Becoming psychologists in Ecuador: A critical ethnography of trainees' professional identity [PhD Thesis]. University College London.

Capella, M., \& Andrade, F. (2017). Hacia una psicología ecuatoriana: Una argumentación intergeneracional sobre la importancia de la cultura y la glocalidad en la investigación. Teoría y Crítica de La Psicología, 9, 173-195.

Cave, J., \& Grieve, K. (2009). Quality of education and neuropsychological test performance. New Voices in Psychology, 5(1), 29-48.

Clouter, A. (2013). The effects of dual n-back training on the components of working memory and fluid intelligence: An individual differences approach [Master Thesis]. Dalhousie University. 
Cohen, J. (1988). Statistical power analysis for the behavioral sciences (2nd ed). L. Erlbaum Associates.

Colom, R., Román, F. J., Abad, F. J., Shih, P. C., Privado, J., Froufe, M., Escorial, S., Martínez, K., Burgaleta, M., Quiroga, M. A., Karama, S., Haier, R. J., Thompson, P. M., \& Jaeggi, S. M. (2013). Adaptive n-back training does not improve fluid intelligence at the construct level: Gains on individual tests suggest that training may enhance visuospatial processing. Intelligence, 41(5), 712-727. https://doi.org/10.1016/j.intell.2013.09.002

Cortese, S., Ferrin, M., Brandeis, D., Buitelaar, J., Daley, D., Dittmann, R. W., Holtmann, M., Santosh, P., Stevenson, J., Stringaris, A., Zuddas, A., \& SonugaBarke, E. J. S. (2015). Cognitive training for Attention-Deficit/Hyperactivity disorder: Meta-analysis of clinical and neuropsychological outcomes from randomized controlled trials. Journal of the American Academy of Child \& Adolescent Psychiatry, 54(3), 164-174. https://doi.org/10.1016/j.jaac.2014.12.010

Cowan, N. (2011). The focus of attention as observed in visual working memory tasks: Making sense of competing claims. Neuropsychologia, 49(6), 1401-1406. https://doi.org/10.1016/j.neuropsychologia.2011.01.035

Diamond, A. (2013). Executive Functions. Annual Review of Psychology, 64(1), 135168. https://doi.org/10.1146/annurev-psych-113011-143750

Dougherty, M. R., Hamovitz, T., \& Tidwell, J. W. (2016). Reevaluating the effectiveness of n-back training on transfer through the Bayesian lens: Support for the null. Psychonomic Bulletin \& Review, 23(1), 306-316. https://doi.org/10.3758/s13423-015-0865-9

Ellis, A. P. J., \& Ryan, A. M. (2003). Race and cognitive-ability test performance: The mediating effects of test preparation, test-taking strategy use and self-efficacy. Journal of Applied Social Psychology, 33(12), 2607-2629. https://doi.org/10.1111/j.1559-1816.2003.tb02783.x 
Faul, F., Erdfelder, E., Lang, A.-G., \& Buchner, A. (2007). G*Power 3: A flexible statistical power analysis program for the social, behavioral, and biomedical sciences. Behavior Research Methods, 39(2), 175-191. https://doi.org/10.3758/BF03193146

Foroughi, C. K., Monfort, S. S., Paczynski, M., McKnight, P. E., \& Greenwood, P. M. (2016). Placebo effects in cognitive training. Proceedings of the National Academy of Sciences, 113(27), 7470-7474. https://doi.org/10.1073/pnas.1601243113

Forstmeier, W., Wagenmakers, E. J., \& Parker, T. H. (2017). Detecting and avoiding likely false-positive findings - a practical guide. Biological Reviews, 92(4), 1941-1968. https://doi.org/10.1111/brv.12315

Gray, J. R., Chabris, C. F., \& Braver, T. S. (2003). Neural mechanisms of general fluid intelligence. Nature Neuroscience, 6(3), 316-322. https://doi.org/10.1038/nn1014

Greene, C. M., Kennedy, K., \& Soto, D. (2015). Dynamic states in working memory modulate guidance of visual attention: Evidence from an n-back paradigm. Visual Cognition, 23(5), 546-560. https://doi.org/10.1080/13506285.2015.1052033

Harrison, T. L., Shipstead, Z., Hicks, K. L., Hambrick, D. Z., Redick, T. S., \& Engle, R. W. (2013). Working memory training may increase working memory capacity but not fluid intelligence. Psychological Science, 24(12), 2409-2419. https://doi.org/10.1177/0956797613492984

Harvey, P.-O., Fossati, P., Pochon, J.-B., Levy, R., LeBastard, G., Lehéricy, S., Allilaire, J.-F., \& Dubois, B. (2005). Cognitive control and brain resources in major depression: An fMRI study using the n-back task. NeuroImage, 26(3), 860-869. https://doi.org/10.1016/j.neuroimage.2005.02.048

Heinzel, S., Schulte, S., Onken, J., Duong, Q.-L., Riemer, T. G., Heinz, A., Kathmann, N., \& Rapp, M. a. (2014). Working memory training improvements and gains in 
non-trained cognitive tasks in young and older adults. Neuropsychology, Development, and Cognition. Section B, Aging, Neuropsychology and Cognition, 21(2), 146-73. https://doi.org/10.1080/13825585.2013.790338

Hill, N. T. M., Mowszowski, L., Naismith, S. L., Chadwick, V. L., Valenzuela, M., \& Lampit, A. (2017). Computerized cognitive training in older adults with mild cognitive impairment or dementia: A systematic review and meta-analysis. American Journal of Psychiatry, 174(4), 329-340. https://doi.org/10.1176/appi.ajp.2016.16030360

Jaeggi, S. M., Buschkuehl, M., Jonides, J., \& Perrig, W. J. (2008). Improving fluid intelligence with training on working memory. Proceedings of the National Academy of Sciences of the United States of America, 105(19), 6829-6833. https://doi.org/10.1073/pnas.0801268105

Jaeggi, S. M., Buschkuehl, M., Perrig, W. J., \& Meier, B. (2010). The concurrent validity of the N-back task as a working memory measure. Memory, 18(4), 394412. https://doi.org/10.1080/09658211003702171

Jaeggi, S. M., Buschkuehl, M., Shah, P., \& Jonides, J. (2014). The role of individual differences in cognitive training and transfer. Memory \& Cognition, 42, 464-80. https://doi.org/10.3758/s13421-013-0364-z

Jaeggi, S. M., Studer-Luethi, B., Buschkuehl, M., Su, Y.-F., Jonides, J., \& Perrig, W. J. (2010). The relationship between n-back performance and matrix reasoningImplications for training and transfer. Intelligence, 38(6), 625-635. https://doi.org/10.1016/j.intell.2010.09.001

Jensen, A. (1998). Construct, vehicles, and measurements. In The g Factor: The Science of Mental Ability (pp. 306-349). Praeger Publishers.

Kane, M. J., Conway, A. R. A., Miura, T. K., \& Colflesh, G. J. H. (2007). Working memory, attention control, and the n-back task: A question of construct validity. Journal of Experimental Psychology: Learning, Memory, and Cognition, 33(3), 615-622. https://doi.org/10.1037/0278-7393.33.3.615 
Kane, M. J., \& Engle, R. W. (2003). Working-memory capacity and the control of attention: The contributions of goal neglect, response competition, and task set to Stroop interference. Journal of Experimental Psychology: General, 132(1), 47-70. https://doi.org/10.1037/0096-3445.132.1.47

Katz, B., Jaeggi, S. M., Buschkuehl, M., Stegman, A., \& Shah, P. (2014). Differential effect of motivational features on training improvements in school-based cognitive training. Frontiers in Human Neuroscience, 8, 10.

Kessler, Y., \& Oberauer, K. (2014). Working memory updating latency reflects the cost of switching between maintenance and updating modes of operation. Journal of Experimental Psychology: Learning, Memory, and Cognition, 40(3), 738-754. https://doi.org/10.1037/a0035545

Klingberg, T., Forssberg, H., \& Westerberg, H. (2002). Training of Working Memory in Children With ADHD. Journal of Clinical and Experimental Neuropsychology, 24(6), 781-791. https://doi.org/10.1076/jcen.24.6.781.8395

Küper, K., \& Karbach, J. (2016). Increased training complexity reduces the effectiveness of brief working memory training: Evidence from short-term single and dual n-back training interventions. Journal of Cognitive Psychology, 28(2), 199-208. http://dx.doi.org/10.1080/20445911.2015.1118106

Lane, T. S., Armin, J., \& Gordon, J. S. (2015). Online recruitment methods for webbased and mobile health studies: A review of the literature. Journal of Medical Internet Research, 17(7), e183. https://doi.org/10.2196/jmir.4359

Li, Q., Long, Q., Hu, N., Tang, Y., \& Chen, A. (2020). N-back task training helps to improve post-error performance. Frontiers in Psychology, 11, 370. https://doi.org/10.3389/fpsyg.2020.00370

Lilienthal, L., Tamez, E., Shelton, J. T., Myerson, J., \& Hale, S. (2013). Dual n-back training increases the capacity of the focus of attention. Psychonomic Bulletin $\&$ Review, 20(1), 135-141. https://doi.org/10.3758/s13423-012-0335-6 
McElree, B. (2001). Working memory and focal attention. Journal of Experimental Psychology. Learning, Memory, and Cognition, 27(3), 817-835. https://doi.org/10.1037/0278-7393.27.3.817

McElree, B. (2006). Accessing recent events. In Psychology of Learning and Motivation (Vol. 46, pp. 155-200). Elsevier. https://doi.org/10.1016/S0079-7421(06)460059

McNab, F., Varrone, A., Farde, L., Jucaite, A., Bystritsky, P., Forssberg, H., \& Klingberg, T. (2009). Change in cortical dopamine D1 receptor binding associated with cognitive training. Science, 323(5915), 800-802. https://doi.org/ 10.1126/science. 1166102

Melby-Lervåg, M., \& Hulme, C. (2013). Is working memory training effective? A metaanalytic review. Developmental Psychology, 49(2), 270-291. https://doi.org/10.1037/a0028228

Melby-Lervåg, M., \& Hulme, C. (2016). There is no convincing evidence that working memory training is effective: A reply to Au et al. (2014) and Karbach and Verhaeghen (2014). Psychonomic Bulletin \& Review, 23(1), 324-330. https://doi.org/10.3758/s13423-015-0862-z

Melby-Lervåg, M., Redick, T. S., \& Hulme, C. (2016). Working memory training does not improve performance on measures of intelligence or other measures of "far transfer": Evidence from a meta-analytic review. Perspectives on Psychological Science, 11(4), 512-534. https://doi.org/10.1177/1745691616635612

Millman, J., Bishop, C. H., \& Ebel, R. (1965). An analysis of test-wiseness. Educational and Psychological Measurement, 25(3), 707-726.

Minear, M., Brasher, F., Guerrero, C. B., Brasher, M., Moore, A., \& Sukeena, J. (2016). A simultaneous examination of two forms of working memory training: Evidence for near transfer only. Memory \& Cognition, 44(7), 1014-1037. https:// doi.org/10.3758/s13421-016-0616-9 
Miyake, A., Friedman, N. P., Emerson, M. J., Witzki, A. H., Howerter, A., \& Wager, T. D. (2000). The unity and diversity of executive functions and their contributions to complex "Frontal Lobe" tasks: A latent variable analysis. Cognitive Psychology, 41(1), 49-100.

Nosek, B. A., Ebersole, C. R., DeHaven, A. C., \& Mellor, D. T. (2018). The preregistration revolution. Proceedings of the National Academy of Sciences, 115(11), 2600-2606. https://doi.org/10.1073/pnas.1708274114

Oberauer, K. (2002). Access to information in working memory: Exploring the focus of attention. Journal of Experimental Psychology: Learning, Memory, and Cognition, 28(3), 411-421. https://doi.org/10.1037/0278-7393.28.3.411

Oberauer, K. (2005). Binding and inhibition in working memory: Individual and age differences in short-term recognition. Journal of Experimental Psychology: General, 134(3), 368-387. https://doi.org/10.1037/0096-3445.134.3.368

Olesen, P. J., Westerberg, H., \& Klingberg, T. (2004). Increased prefrontal and parietal activity after training of working memory. Nature Neuroscience, 7(1), 75-79. https://doi.org/10.1038/nn1165

Olivers, C. N. L., Peters, J., Houtkamp, R., \& Roelfsema, P. R. (2011). Different states in visual working memory: When it guides attention and when it does not. Trends in Cognitive Sciences, S1364661311000854. https://doi.org/10.1016/j.tics.2011.05.004

Owen, A. M., McMillan, K. M., Laird, A. R., \& Bullmore, E. (2005). N-back working memory paradigm: A meta-analysis of normative functional neuroimaging studies. Human Brain Mapping, 25(1), 46-59. https://doi.org/10.1002/hbm.20131

Payne, J. L. (1974). Fishing expedition probability: The statistics of post hoc hypothesizing. Polity, 7(1), 130-138. https://doi.org/10.2307/3234273

Peijnenborgh, J. C. A. W., Hurks, P. M., Aldenkamp, A. P., Vles, J. S. H., \& Hendriksen, J. G. M. (2016). Efficacy of working memory training in children and 
adolescents with learning disabilities: A review study and meta-analysis. Neuropsychological Rehabilitation, 26(5-6), 645-672. https://doi.org/10.1080/09602011.2015.1026356

Peirce, J. W. (2008). Generating stimuli for neuroscience using PsychoPy. Frontiers in Neuroinformatics, 2, 10. https://doi.org/10.3389/neuro.11.010.2008

Redick, T. S., \& Lindsey, D. R. B. (2013). Complex span and n-back measures of working memory: A meta-analysis. Psychonomic Bulletin \& Review, 20(6), 1102-1113. https://doi.org/10.3758/s13423-013-0453-9

Redick, T. S., Shipstead, Z., Harrison, T. L., Hicks, K. L., Fried, D. E., Hambrick, D. Z., Kane, M. J., \& Engle, R. W. (2013). No evidence of intelligence improvement after working memory training: A randomized, placebo-controlled study. Journal of Experimental Psychology: General, 142(2), 359-379. https://doi.org/10.1037/ a0029082

Rinne, T., Koistinen, S., Salonen, O., \& Alho, K. (2009). Task-dependent activations of human auditory cortex during pitch discrimination and pitch memory tasks. Journal of Neuroscience, 29(42), 13338-13343. https://doi.org/10.1523/JNEUROSCI.3012-09.2009

Robertson, I. H., Manly, T., Andrade, J., Baddeley, B. T., \& Yiend, J. (1997). 'Oops!': Performance correlates of everyday attentional failures in traumatic brain injured and normal subjects. Neuropsychologia, 35(6), 747-758. https://doi.org/10.1016/ S0028-3932(97)00015-8

Rodas, J. A., \& Greene, C. (2020a). Test-retest reliability of four cognitive tasks in a not so WEIRD sample [Preprint]. PsyArXiv. https://doi.org/10.31234/osf.io/e2kr7

Rodas, J. A., \& Greene, C. (2020b). Small improvements in working memory after cognitive training do not transfer to fluid intelligence: Evidence from a metaanalysis [Preprint]. PsyArXiv. https://doi.org/10.31234/osf.io/9j64y 
Rogers, W. T., \& Bateson, D. J. (1991). Verification of a model of test-taking behavior of high school seniors. The Journal of Experimental Education, 59(4), 331-350. https://doi.org/10.1080/00220973.1991.10806571

Rosselli, M., \& Ardila, A. (2003). The impact of culture and education on non-verbal neuropsychological measurements: A critical review. Brain and Cognition, 52(3), 326-333. https://doi.org/10.1016/S0278-2626(03)00170-2

Rosvold, H. E., Mirsky, A. F., Sarason, I., Bransome Jr, E. D., \& Beck, L. H. (1956). A continuous performance test of brain damage. Journal of Consulting Psychology, 20(5), 343.

Sala, G., \& Gobet, F. (2017). Does far transfer exist? Negative evidence from chess, music, and working memory training. Current Directions in Psychological Science, 26(6), 515-520. http://dx.doi.org/10.1177/0963721417712760

Salminen, T., Strobach, T., \& Schubert, T. (2012). On the impacts of working memory training on executive functioning. Frontiers in Human Neuroscience, 6. https://doi.org/10.3389/fnhum.2012.00166

Sarnacki, R. E. (1979). An examination of test-wiseness in the cognitive test domain. Review of Educational Research, 49(2), 252-279.

Schmiedek. (2010). Hundred days of cognitive training enhance broad cognitive abilities in adulthood: Findings from the COGITO study. Frontiers in Aging Neuroscience. https://doi.org/10.3389/fnagi.2010.00027

Schmiedek, F. (2016). Methods and designs. In T. Strobach \& J. Karbach (Eds.), Cognitive training: An overview of features and applications (pp. 9-18). Springer. https://doi.org/10.1007/978-3-319-42662-4

Schwaighofer, M., Fischer, F., \& Bühner, M. (2015). Does working memory training transfer? A meta-analysis including training conditions as moderators. Educational Psychologist, 50(2), 138-166. http://dx.doi.org/10.1080/00461520.2015.1036274 
Shipstead, Z., Redick, T. S., \& Engle, R. W. (2012). Is working memory training effective? Psychological Bulletin, 138(4), 628-654. https://doi.org/10.1037/a0027473

Shuttleworth-Edwards, A. B., Kemp, R. D., Rust, A. L., Muirhead, J. G. L., Hartman, N. P., \& Radloff, S. E. (2004). Cross-cultural effects on IQ test performance: A review and preliminary normative indications on WAIS-III test performance. Journal of Clinical and Experimental Neuropsychology, 26(7), 903-920. https:// doi.org/10.1080/13803390490510824

Silver, H., \& Feldman, P. (2005). Evidence for sustained attention and working memory in schizophrenia sharing a common mechanism. The Journal of Neuropsychiatry and Clinical Neurosciences, 17(3), 391-398. https://doi.org/10.1176/jnp.17.3.391

Simons, D. J., Boot, W. R., Charness, N., Gathercole, S. E., Chabris, C. F., Hambrick, D. Z., \& Stine-Morrow, E. A. L. (2016). Do “brain-training” programs work? Psychological Science in the Public Interest, 17(3), 103-186. https://doi.org/10.1177/1529100616661983

Smith, G. E., Housen, P., Yaffe, K., Ruff, R., Kennison, R. F., Mahncke, H. W., \& Zelinski, E. M. (2009). A cognitive training program based on principles of brain plasticity: Results from the Improvement in Memory with Plasticity-based Adaptive Cognitive Training (impact) study. Journal of the American Geriatrics Society, 57(4), 594-603. https://doi.org/10.1111/j.1532-5415.2008.02167.x

Soveri, A., Karlsson, E. P. A., Waris, O., Grönholm-Nyman, P., \& Laine, M. (2017). Pattern of near transfer effects following working memory training with a dual n-back task. Experimental Psychology, 64(4), 240-252. https://doi.org/10.1027/1618-3169/a000370

Stephenson, C. L., \& Halpern, D. F. (2013). Improved matrix reasoning is limited to training on tasks with a visuospatial component. Intelligence, 41(5), 341-357. https://doi.org/10.1016/j.intell.2013.05.006 
Sterne, J., Savović, J., Page, M., Elbers, R., Blencowe, N., Boutron, I., Cates, C., Cheng, H.-Y., Corbett, M., Eldridge, S., Hernán, M., Hopewell, S., Hróbjartsson, A., Junqueira, D., Jüni, P., Kirkham, J., Lasserson, T., Li, T., McAleenan, A., ... Higgins, J. (2019). RoB 2: A revised tool for assessing risk of bias in randomised trials. $B M J, 366(14898)$.

https://sites.google.com/site/riskofbiastool/welcome/rob-2-0-tool/currentversion-of-rob-2?authuser $=0$

Stroop, J. R. (1935). Studies of interference in serial verbal reactions. Journal of Experimental Psychology, 18(6), 643-662.

Studer-Luethi, B., Jaeggi, S. M., Buschkuehl, M., \& Perrig, W. J. (2012). Influence of neuroticism and conscientiousness on working memory training outcome. Personality and Individual Differences, 53(1), 44-49. https://doi.org/10.1016/j.paid.2012.02.012

Swaen, G. G., Teggeler, O., \& van Amelsvoort, L. G. (2001). False positive outcomes and design characteristics in occupational cancer epidemiology studies. International Journal of Epidemiology, 30(5), 948-954. https://doi.org/10.1093/ije/30.5.948

Takahashi, M., Iwamoto, K., Fukatsu, H., Naganawa, S., Iidaka, T., \& Ozaki, N. (2010). White matter microstructure of the cingulum and cerebellar peduncle is related to sustained attention and working memory: A diffusion tensor imaging study. Neuroscience Letters, 477(2), 72-76. https://doi.org/10.1016/j.neulet.2010.04.031

Verbruggen, F., Logan, G. D., \& Stevens, M. A. (2008). STOP-IT: Windows executable software for the stop-signal paradigm. Behavior Research Methods, 40(2), 479483. https://doi.org/10.3758/BRM.40.2.479

Verhaeghen, P., Cerella, J., \& Basak, C. (2004). A working memory workout: How to expand the focus of serial attention from one to four items in 10 hours or less. 
Journal of Experimental Psychology: Learning, Memory, and Cognition, 30(6), 1322-1337. https://doi.org/10.1037/0278-7393.30.6.1322

Ward, N., Paul, E., Watson, P., Cooke, G. E., Hillman, C. H., Cohen, N. J., Kramer, A. F., \& Barbey, A. K. (2017). Enhanced learning through multimodal training: Evidence from a comprehensive cognitive, physical fitness, and neuroscience intervention. Scientific Reports, 7(1), 5808. https://doi.org/10.1038/s41598-017$06237-5$

Waris, O., Soveri, A., Ahti, M., Hoffing, R. C., Ventus, D., Jaeggi, S. M., Seitz, A. R., \& Laine, M. (2017). A latent factor analysis of working memory measures using large-scale data. Frontiers in Psychology, 8, 1062. https://doi.org/10.3389/fpsyg.2017.01062

Welsh, M. C., Pennington, B. F., \& Groisser, D. B. (1991). A normative-developmental study of executive function: A window on prefrontal function in children. Developmental Neuropsychology, 7(2), 131-149. https://doi.org/10.1080/87565649109540483

Willing, S., Ostapczuk, M., \& Musch, J. (2015). Do sequentially-presented answer options prevent the use of testwiseness cues on continuing medical education tests? Advances in Health Sciences Education, 20(1), 247-263. https://doi.org/10.1007/s10459-014-9528-2 


\section{Table 1}

Descriptive statistics and interaction between factors from ANOVAs of all outcome scores

\begin{tabular}{|c|c|c|c|c|c|c|c|c|c|c|c|}
\hline \multirow{3}{*}{ Measure } & \multicolumn{5}{|c|}{ Experimental } & \multicolumn{5}{|c|}{ Control } & \multirow{3}{*}{$\begin{array}{c}\text { Effect of training } \\
\text { (group } \mathrm{x} \text { time interaction) }\end{array}$} \\
\hline & \multicolumn{3}{|c|}{ Pre } & \multicolumn{2}{|c|}{ Post } & \multicolumn{3}{|c|}{ Pre } & \multicolumn{2}{|c|}{ Post } & \\
\hline & $\mathrm{N}$ & $\mathrm{M}$ & SD & M & SD & $\mathrm{N}$ & $\mathrm{M}$ & SD & $\mathrm{M}$ & SD & \\
\hline Test of non-verbal intelligence & 40 & 15.675 & 3.245 & 15.75 & 4.738 & 54 & 14.37 & 3.662 & 16.389 & 2.811 & $\mathrm{~F}(1,92)=5.5, \mathrm{p}=0.021, \eta_{\mathrm{p}}^{2}=0.056$ \\
\hline \multicolumn{12}{|l|}{ Short-term memory } \\
\hline Backward digit span & 42 & 6 & 1.7 & 6.571 & 2.221 & 54 & 5.667 & 1.554 & 5.796 & 1.571 & $\mathrm{~F}(1,94)=1.759, \mathrm{p}=0.188, \eta_{\mathrm{p}}^{2}=0.018$ \\
\hline \multicolumn{12}{|l|}{ Focus of attention } \\
\hline Columns n-back & 42 & 0.412 & 0.28 & 0.301 & 0.19 & 55 & 0.472 & 0.252 & 0.361 & 0.247 & $\mathrm{~F}(1,95)=<0.001, \mathrm{p}=0.9, \eta_{\mathrm{p}}^{2}=<0.001$ \\
\hline Columns n-back errors n1 & 42 & 1.571 & 2.339 & 1.31 & 1.615 & 55 & 1.8 & 2.313 & 0.8 & 1.043 & $\mathrm{~F}(1,95)=2.39, \mathrm{p}=0.13, \eta_{\mathrm{p}}^{2}=0.025$ \\
\hline Columns n-back errors n2 & 42 & 7.905 & 7.583 & 4.857 & 5.625 & 55 & 6.891 & 3.924 & 4.764 & 4.517 & $F(1,95)=0.78, p=0.38, \eta_{p}^{2}=0.008$ \\
\hline Rapid span & 42 & 2.85 & 0.482 & 3.033 & 0.493 & 55 & 2.844 & 0.592 & 3.07 & 0.444 & $\mathrm{~F}(1,95)=0.22, \mathrm{p}=0.64, \eta_{\mathrm{p}}^{2}=0.002$ \\
\hline \multicolumn{12}{|l|}{ Focus switching } \\
\hline Arithmetic-Updating sw & 41 & 3.745 & 1.974 & 3.259 & 1.634 & 55 & 4.169 & 1.868 & 3.354 & 1.242 & $\mathrm{~F}(1,94)=1.36, \mathrm{p}=0.25, \eta_{\mathrm{p}}^{2}=0.014$ \\
\hline Arithmetic-Updating correct & 41 & 3.902 & 1.158 & 3.927 & 1.17 & 55 & 3.855 & 1.283 & 4.145 & 1.044 & $F(1,94)=0.86, p=0.36, \eta_{p}^{2}=0.009$ \\
\hline Letter-Updating & 42 & 10.638 & 4.777 & 8.416 & 4.732 & 55 & 10.944 & 5.352 & 8.103 & 2.971 & $F(1,95)=0.58, p=0.45, \eta_{p}^{2}=0.006$ \\
\hline
\end{tabular}


Inhibition

Stop-Signal SSRT

Stroop cost

Stroop errors

Sustained attention

CPT omissions

CPT mean RT

SART

Updating

Arithmetic-Updating

Letter Memory $\begin{array}{lllll}40 & 251.058 & 95.003 & 246.223 & 98.071\end{array}$

$\begin{array}{lllll}42 & 0.256 & 0.191 & 4.982 & 4.635\end{array}$

$42 \quad 5.238$

$\begin{array}{lll}4.584 & 5.881 \quad 3.877\end{array}$

$42 \quad 9.905 \quad 7.685$

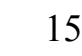

$42 \quad 0.60$

$42 \quad 9.95$

$41 \quad 3.321$

1.258

2.884

1.098

$42 \quad 37.595$

$11.043 \quad 37.405 \quad 10.439$
52

215.708

85.128

227.913

82.644

$F(1,90)=0.92, p=0.34, \eta_{p}^{2}=0.01$

$\begin{array}{ll}56 & 0.304\end{array}$

0.183

4.374

4.741

$56 \quad 4.679$

4.699

4.75

4.028

$F(1,96)=0.46, p=0.5, \eta_{p}^{2}=0.005$

$F(1,96)=0.32, p=0.57, \eta_{p}^{2}=0.003$
$F(1,94)=0.23, p=0.63, \eta_{p}^{2}=0.002$

$F(1,94)=0.13, p=0.72, \eta_{p}^{2}=0.001$

$F(1,96)=0.17, p=0.68, \eta_{p}^{2}=0.002$

$55 \quad 3.424$

1.555

3.11

1.272

$F(1,94)=0.29, p=0.59, \eta_{p}^{2}=0.003$

$56 \quad 36.518$

9.363

39.696

8.261

$F(1,96)=3.26, p=0.07, \eta_{p}^{2}=0.033$ 


\section{Figure 1}

\section{Depiction of assessment tasks presenting visual stimuli}

Test of Non-Verbal Intelligence

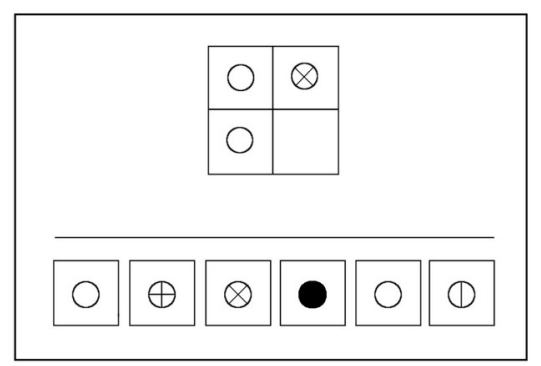

e

Letter Memory Task

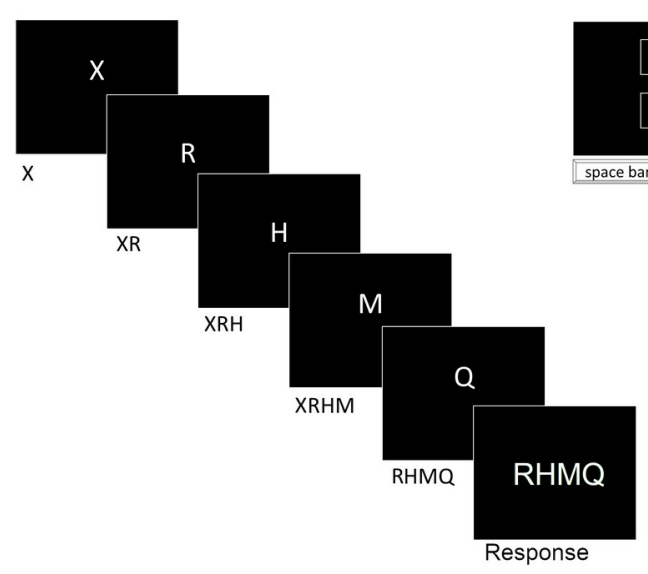

b

Columns n-back Task

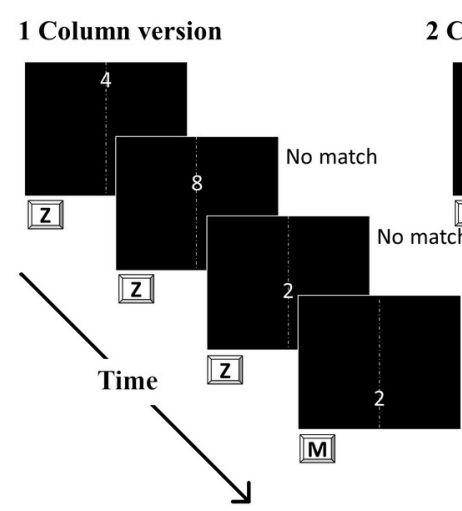

f

Arithmetic-Updating Task

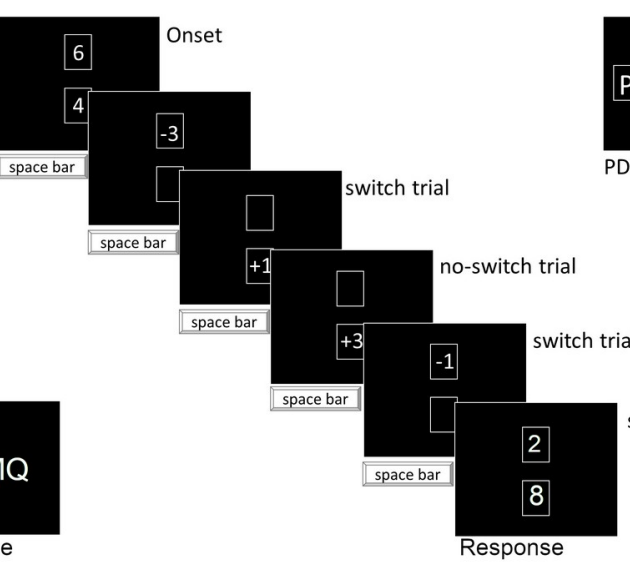

Stop-Signal Task

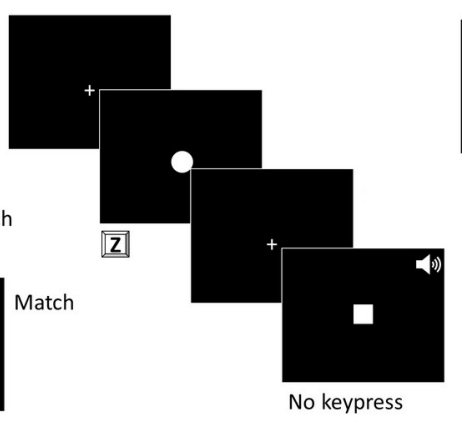

M

Letter-Updating Task

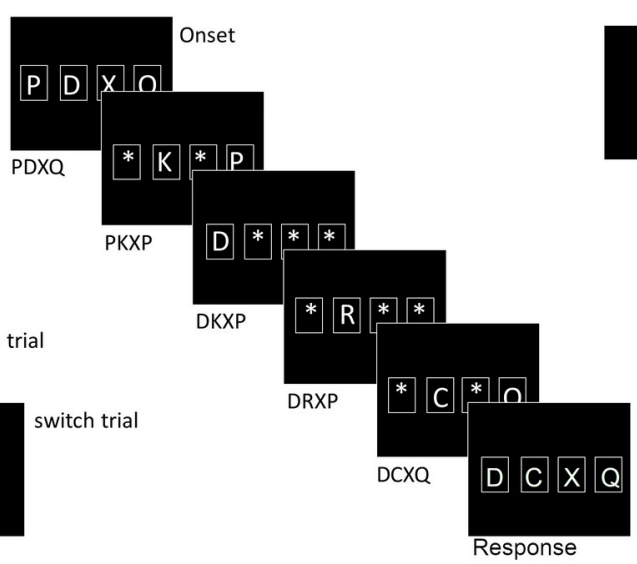

d

Colour Word Stroop Task

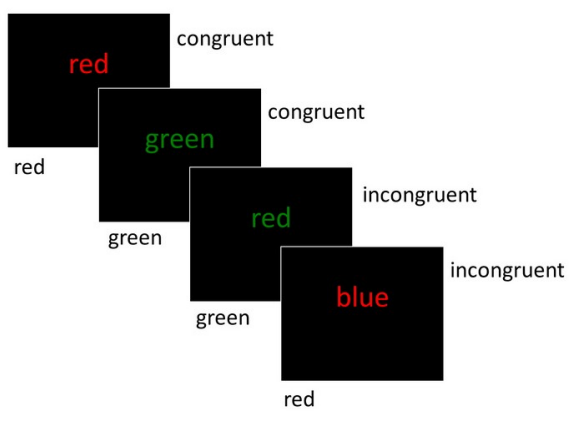

Sustained Attention to Response Task

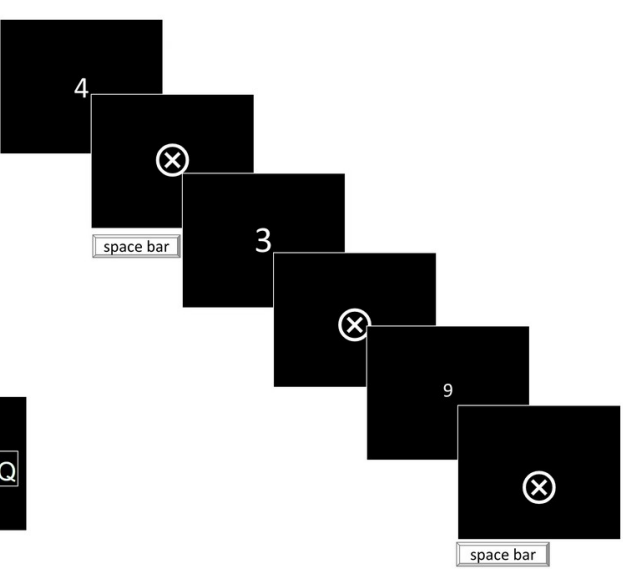


Sample trials from each of the visual tasks used in the study. a) Columns n-back task. Participants press M to indicate a match (same number in same column) and $\mathrm{Z}$ to indicate no-match. The dotted lines are for illustrative purposes only and were not presented during the task. b) Stop-Signal Task. Participants press $\mathrm{Z}$ in response to the target (circle or square) unless the auditory stop signal is presented. c) Colour Word Stroop. Participants indicate the font colour of the presented word while ignoring the meaning of the word. d) Test of Non-Verbal Intelligence. Participants must choose the appropriate pattern to complete the sequence. e) Letter Memory Task. Letters are presented singly, and when prompted, participants must recall the last four letters. f) Arithmetic-Updating Task. The participant maintains a running total of the arithmetic operations presented in the top and bottom boxes, and enters their final value when prompted. g) Letter-Updating Task. Participants must recall (asterisk) or update (new letter) their memory of letters presented in four boxes, and provide the final values for each box when prompted. h) Sustained Attention to Response Task. Participants respond to every stimulus except the number 3 . 


\section{Figure 2}

Depiction of 1-back and 2-back tasks used for training

a

Visuospatial 1-back Task

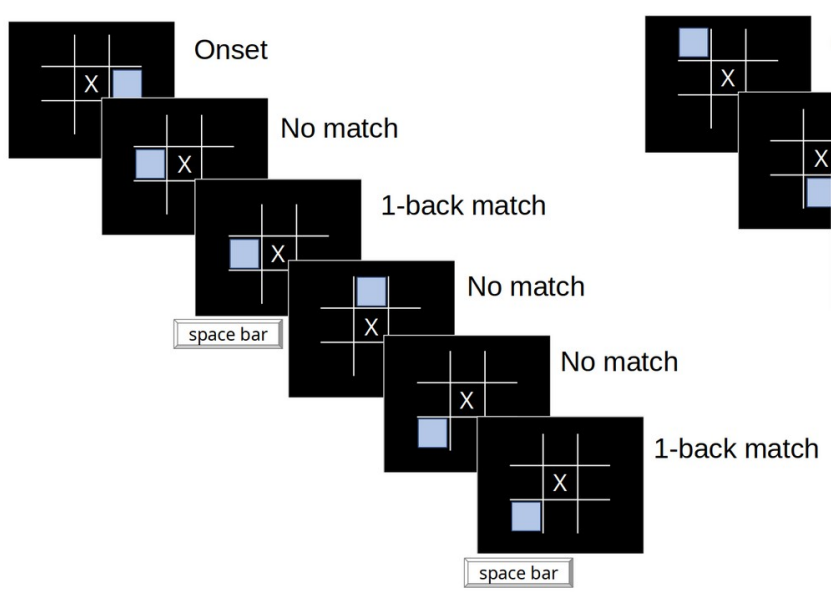

b

Visuospatial 2-back Task

Onset

No match

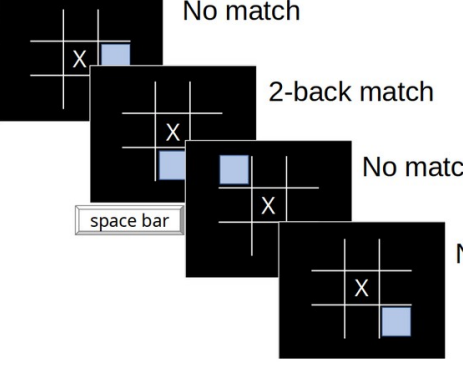

Sample trials from a 1-back and 2-back task. a) Participants indicate whether the location of a square matches the location one trial previously. b) Participants indicate whether the location of a square matches the location two trials previously (2-back). 
Figure 3

$N$-back task performance across training sessions for experimental group

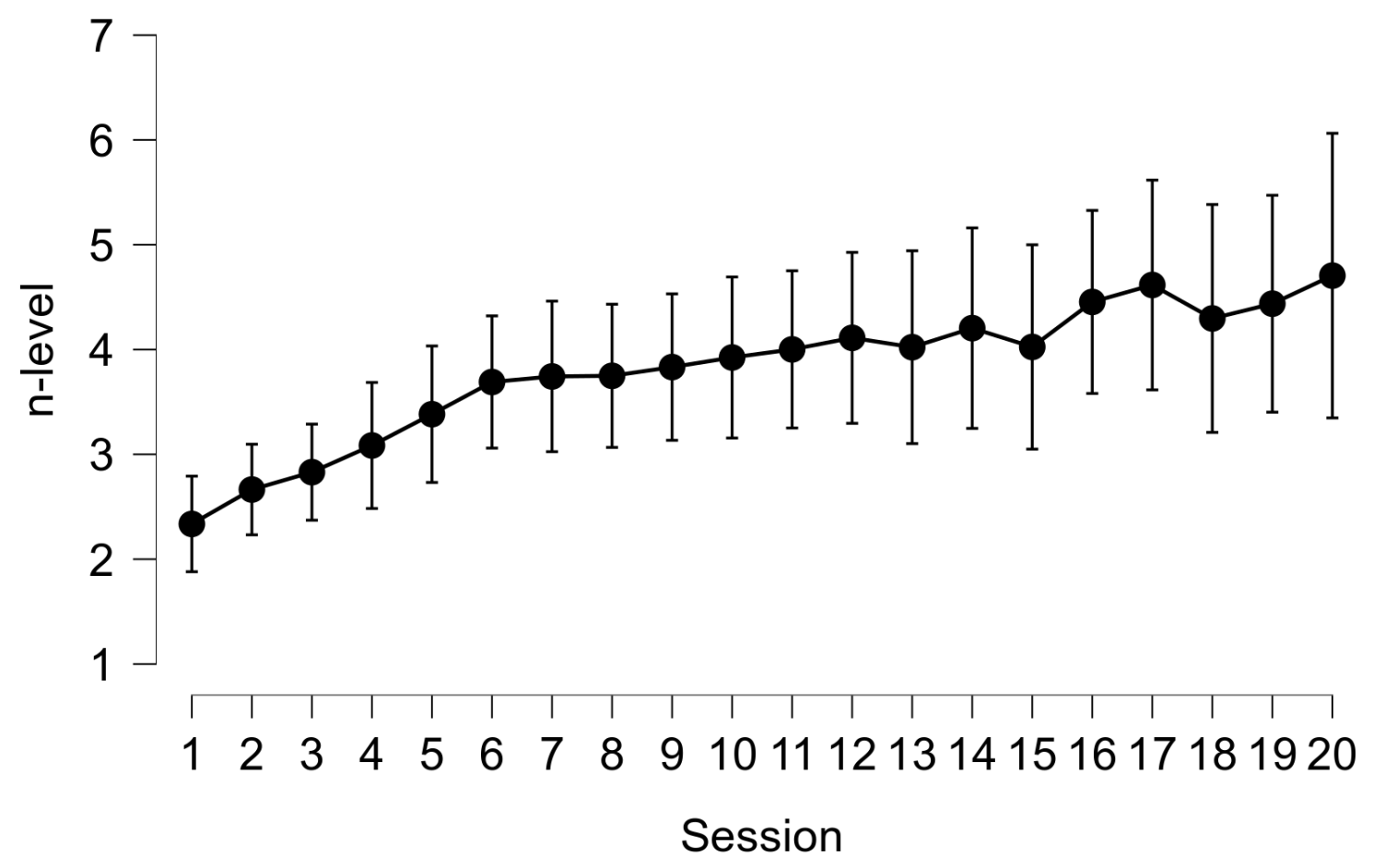

Note. Each point represent the mean $n$ score achieved with their corresponding standard errors. 